Article

\title{
Hybrid Methods for a Countable Family of G-Nonexpansive Mappings in Hilbert Spaces Endowed with Graphs
}

\author{
Suthep Suantai ${ }^{1}$, Mana Donganont ${ }^{2}\left(\mathbb{D}\right.$ and Watcharaporn Cholamjiak ${ }^{2, *(D)}$ \\ 1 Data Science Research Center, Department of Mathematics, Faculty of Science, Chiang Mai University, \\ Chiang Mai 50200, Thailand; suthep.s@cmu.ac.th \\ 2 School of Science, University of Phayao, Phayao 56000, Thailand; Doodeejung002@gmail.com \\ * Correspondence: watcharaporn.ch@up.ac.th
}

Received: 26 June 2019; Accepted: 2 October 2019; Published: 10 October 2019

check for updates

\begin{abstract}
In this paper, we introduce the iterative scheme for finding a common fixed point of a countable family of G-nonexpansive mappings by the shrinking projection method which generalizes Takahashi Takeuchi and Kubota's theorem in a Hilbert space with a directed graph. Simultaneously, we give examples and numerical results for supporting our main theorems and compare the rate of convergence of some examples under the same conditions.
\end{abstract}

Keywords: G-nonexpansive mapping; hybrid method; NST-condition; iteration; Hilbert space

\section{Introduction}

In this paper, we assume that $H$ is a real Hilbert space with inner product $\langle\cdot, \cdot\rangle$ and norm $\|\cdot\|$. Let $C$ be a nonempty subset of $H$. Then, mapping $T: C \rightarrow C$ is called

1. contraction if there exists $\alpha \in(0,1)$ such that $\|T x-T y\| \leq \alpha\|x-y\|$ for all $x, y \in C$;

2. nonexpansive if $\|T x-T y\| \leq\|x-y\|$ for all $x, y \in C$.

An element $z \in C$ is called a fixed point of $T$ if $z=T z$. The fixed point set of $T$ is denoted by $F(T)$. There are many iterative methods for approximating fixed points of nonexpansive mapping in a Hilbert space (see [1-3]) and references therein.

In 1953, Mann [2] introduced the iteration procedure as follows:

$$
x_{1} \in C, x_{n+1}=\alpha_{n} x_{n}+\left(1-\alpha_{n}\right) T x_{n}, \forall n \in \mathbb{N},
$$

where $\left\{\alpha_{n}\right\} \subset[0,1]$ and $\mathbb{N}$ are the set of all positive integers. Recently, many mathematicians (see [4-6]) have used Mann's iteration for obtaining a weak convergence theorem.

Let $H$ be a Hilbert space and let $C$ be a subset of $H$. Let $\left\{T_{n}\right\}$ and $\tau$ be two families of mappings of $C$ into itself with $\varnothing \neq F(\tau)=\bigcap_{n=1}^{\infty} F\left(T_{n}\right)$, where $F\left(T_{n}\right)$ is the set of all fixed points of $T_{n}, F(\tau)$ is the set of all common fixed points of $\tau .\left\{T_{n}\right\}$ is said to satisfy the NST-condition [7] with respect to $\tau$ if for each bounded sequence $\left\{z_{n}\right\}$ in $C$,

$$
\lim _{n \rightarrow \infty}\left\|z_{n}-T_{n} z_{n}\right\|=0 \Rightarrow \lim _{n \rightarrow \infty}\left\|z_{n}-T z_{n}\right\|=0, \forall T \in \tau .
$$

To obtain a strong convergence theorem, Takahashi et al. [8] introduced the following modification of the Mann's iteration method (1), which just involved one closed convex set for a countable family of nonexpansive mappings $\left\{T_{n}\right\}$, which is called the shrinking projection method: 
Theorem 1. Let $H$ be a Hilbert space and $C$ be a nonempty closed convex subset of $H$ [8]. Let $\left\{T_{n}\right\}$ and $\tau$ be a family of nonexpansive mappings of $C$ into $H$ such that $F:=\cap_{n=1}^{\infty} F\left(T_{n}\right)=F(\tau) \neq \varnothing$ and let $x_{0} \in H$. Suppose that $\left\{T_{n}\right\}$ satisfies the NST-condition with $\tau$. For $C_{1}=C$ and $u_{1}=P_{C_{1}} x_{0}$, define a sequence $\left\{u_{n}\right\}$ in $C$ as follows:

$$
\left\{\begin{array}{l}
y_{n}=\alpha_{n} u_{n}+\left(1-\alpha_{n}\right) T_{n} u_{n} \\
C_{n+1}=\left\{z \in C_{n}:\left\|y_{n}-z\right\| \leq\left\|u_{n}-z\right\|\right\} \\
u_{n+1}=P_{C_{n+1}} x_{0}, \quad \forall n \in \mathbb{N}
\end{array}\right.
$$

where $0 \leq \alpha_{n} \leq a<1$ for all $n \in \mathbb{N}$. Then, the sequence $\left\{u_{n}\right\}$ converges strongly to a point $z_{0}=P_{F} x_{0}$.

This iteration is used to obtain strong convergence theorem (see, for example, $[9,10])$.

Let $X$ be a Banach space and $C$ be a nonempty subset of $X$. Let $G$ be a directed graph with the set of vertices $V(G)=C$ and the set of edges $E(G)$ that contains the diagonal of $C \times C$, where an edge $(x, y) \in E(G)$ is the related pairs of vertices $x$ and $y$. We suppose that $G$ has no parallel edge.

Thus, we can identify the graph $G$ with the pair $(V(G), E(G))$. A mapping $T: C \rightarrow C$ is said to be 1. G-contraction if $T$ satisfies the conditions:

(i) $T$ preserves edges of $G$, i.e.,

$$
(x, y) \in E(G) \Rightarrow(T x, T y) \in E(G), \forall(x, y) \in E(G)
$$

(ii) $T$ decreases weights of edges of $G$ in the following way: there exists $\alpha \in(0,1)$ such that

$$
(x, y) \in E(G) \Rightarrow\|T x-T y\| \leq \alpha\|x-y\|, \forall(x, y) \in E(G)
$$

2. G-nonexpansive if $T$ satisfies the conditions:

(i) $T$ preserves edges of $G$, i.e.,

$$
(x, y) \in E(G) \Rightarrow(T x, T y) \in E(G), \forall(x, y) \in E(G)
$$

(ii) $T$ non-increases weights of edges of $G$ in the following way:

$$
(x, y) \in E(G) \Rightarrow\|T x-T y\| \leq\|x-y\|, \forall(x, y) \in E(G) .
$$

In 2008, Jachymski [11] proved some generalizations of the Banach's contraction principle in complete metric spaces endowed with a graph. To be more precise, Jachymski proved the following result.

Theorem 2. Let $(X, d)$ be a complete metric space, and a triple $(X, d, G)$ have the following property: for any sequence $\left\{x_{n}\right\}$ if $x_{n} \rightarrow x$ and $\left(x_{n}, x_{n+1}\right) \in E(G)$ for $n \in \mathbb{N}$ and there is a subsequence $\left\{x_{n_{k}}\right\}$ of $\left\{x_{n}\right\}$ with $\left(x_{n_{k}}, x\right) \in E(G)$ for all $n \in \mathbb{N}$.

Let $T: X \rightarrow X$ be a G-contraction, and $X_{T}=\{x \in X:(x, T x) \in E(G)\}$. Then, $F(T) \neq \varnothing$ if and only if $X_{T} \neq \varnothing[11]$.

In 2008, Tiammee et al. [12] and Alfuraidan [13] employed the above theorem to establish the existence and the convergence results for G-nonexpansive mappings with graphs. Recently, many mathematicians (see [14,15]) have introduced the iterative method for finding a fixed point of G-nonexpansive mappings in the framework of Hilbert spaces and Banach spaces.

Inspired by all aforementioned references, we introduce the iterative scheme for solving the fixed point problem of a countable family of G-nonexpansive mappings. We also obtain strong convergence theorems in a Hilbert space with a directed graph under suitable conditions. Furthermore, we demonstrate examples and numerical results for supporting our main results and compare the rate of convergence of some examples under the same conditions. 


\section{Preliminaries and Lemmas}

We now provide some basic results for the proof. In a Hilbert space $H$, let $C$ be a nonempty closed and convex subset of $H$. Letting $\left\{x_{n}\right\}$ be a sequence in $H$, we denote the weak convergence of $\left\{x_{n}\right\}$ to a point $x \in H$ by $x_{n} \rightarrow x$ and the strong convergence, that is, relative to a norm of $\left\{x_{n}\right\}$ to a point $x \in H$ by $x_{n} \rightarrow x$. For every point $x \in H$, there exists a unique nearest point of $C$, denoted by $P_{C} x$, such that $\left\|x-P_{C} x\right\| \leq\|x-y\|$ for all $y \in C$. Such a $P_{C}$ is called the metric projection from $H$ onto $C$.

Lemma 1. Let $H$ be a real Hilbert space [16]. Then, for each $x, y \in H$ and each $t \in[0,1]$,

(a) $\|x-y\|^{2}=\|x\|^{2}-2\langle x, y\rangle+\|y\|^{2}$,

(b) $\|t x+(1-t) y\|^{2}=t\|x\|^{2}+(1-t)\|y\|^{2}-t(1-t)\|x-y\|^{2}$,

(c) If $\left\{x_{n}\right\}$ is a sequence in $H$ weakly convergent to $z$, then $\lim \sup _{n \rightarrow \infty}\left\|x_{n}-y\right\|^{2}=\lim _{\sup _{n \rightarrow \infty}} \| x_{n}-$ $z\left\|^{2}+\right\| z-y \|^{2}$.

Lemma 2. Let $C$ be a nonempty closed and convex subset of a real Hilbert space $H$ [17]. For each $x, y \in H$ and $a \in \mathbb{R}$, the set

$$
D=\left\{v \in C:\|y-v\|^{2} \leq\|x-v\|^{2}+\langle z, v\rangle+a\right\}
$$

is closed and convex.

Lemma 3. Let $C$ be a nonempty closed and convex subset of a real Hilbert space $H$ and $P_{C}: H \rightarrow C$ be the metric projection from $H$ onto $C$. Then, $\left\|y-P_{c} x\right\|^{2}+\left\|x-P_{c} x\right\|^{2} \leq\|x-y\|^{2}$, for all $x \in H$ and $y \in C$ [18].

Lemma 4. Let $H$ be a real Hilbert space and let $\left\{x_{i}\right\}_{i=1}^{m} \subseteq H$ [19]. For $\alpha_{i} \in(0,1), i=1,2, \ldots, m$ such that $\sum_{i=1}^{m} \alpha_{i}=1$, the following identity holds:

$$
\left\|\sum_{i=1}^{m} \alpha_{i} x_{i}\right\|^{2}=\sum_{i=1}^{m} \alpha_{i}\left\|x_{i}\right\|^{2}-\sum_{1 \leq i<j \leq m} \alpha_{i} \alpha_{j}\left\|x_{i}-x_{j}\right\|^{2} .
$$

Lemma 5. [20] Let $X$ be a Banach space. Then, $X$ is strictly convex, if

$$
\|x\|=\|y\|=\|\lambda x+(1-\lambda) y\|
$$

for all $x, y \in X$ and $\lambda \in(0,1)$, which implies $x=y$.

Definition 1. A directed graph $G$ is transitive if, for any $x, y, z \in V(G)$ in which $(x, y)$ and $(y, z)$ are in $E(G)$, then we have $(x, z) \in E(G)$.

Definition 2. Let $x_{0} \in V(G)$ and $A$ be a subset of $V(G)$. We say that

(i) $A$ is dominated by $x_{0}$ if $\left(x_{0}, x\right) \in E(G)$ for all $x \in A$.

(ii) A dominates $x_{0}$ if, for each $x \in A,\left(x, x_{0}\right) \in E(G)$.

Definition 3. Let $G=(V(G), E(G))$ be a directed graph. The set of edges $E(G)$ is said to be convex if $\left(x_{i}, y_{i}\right) \in E(G)$ for all $i=1,2, \ldots, N$ and $\alpha_{i} \in(0,1)$ such that $\sum_{i=1}^{N} \alpha_{i}=1$, then $\left(\sum_{i=1}^{N} \alpha_{i} x_{i}, \sum_{i=1}^{N} \alpha_{i} y_{i}\right) \in$ $E(G)$.

Lemma 6. Let $C$ be a nonempty, closed and convex subset of a Hilbert space $H$ and $G=(V(G), E(G))$ a directed graph such that $V(G)=C$ [14]. Let $T: C \rightarrow C$ be a G-nonexpansive mapping and $\left\{x_{n}\right\}$ be a sequence in $C$ such that $x_{n} \rightarrow x$ for some $x \in C$. If there exists a subsequence $\left\{x_{n_{k}}\right\}$ of $\left\{x_{n}\right\}$ such that $\left(x_{n_{k}}, x\right) \in E(G)$ for all $k \in \mathbb{N}$ and $\left\{x_{n}-T x_{n}\right\} \rightarrow y$ for some $y \in H$. Then, $(I-T) x=y$. 


\section{Main Results}

In this section, we prove a strong convergence theorem by hybrid methods for families of G-nonexpansive mappings

Theorem 3. Let $H$ be a real Hilbert space and $C$ be a nonempty, closed and convex subset of $H$. Let $G=$ $(V(G), E(G))$ be a directed graph with $V(G)=C$ and $E(G)$ be also convex. Suppose that $\left\{T_{n}\right\}$ and $\tau$ are two families of $G$-nonexpansive mappings on $C$ such that $F(\tau)=\bigcap_{n=1}^{\infty} F\left(T_{n}\right) \neq \varnothing$ and $F(\tau)$ is closed. Assume that $F(T) \times F(T) \subseteq E(G)$ for all $T \in \tau,\left\{T_{n}\right\}$ satisfies the NST-condition with respect to $\tau$ and $0 \leq \alpha_{n} \leq a<1$ for all $n \in \mathbb{N}$. For $x_{0} \in C, C_{1}=C$ and $x_{1}=P_{C_{1}} x_{0}$, define a sequence $\left\{x_{n}\right\}$ of $C$ as follows:

$$
\left\{\begin{array}{l}
y_{n}=\alpha_{n} x_{n}+\left(1-\alpha_{n}\right) T_{n} x_{n} \\
C_{n+1}=\left\{z \in C_{n}:\left\|y_{n}-z\right\| \leq\left\|x_{n}-z\right\|\right\} \\
x_{n+1}=P_{C_{n+1}} x_{0}, \quad n \in \mathbb{N} .
\end{array}\right.
$$

If $\left\{x_{n}\right\}$ satisfies the following conditions:

(i) $\left\{x_{n}\right\}$ dominates $p$ for all $p \in F(\tau)$;

(ii) if there exist a subsequence $\left\{x_{n_{k}}\right\}$ of $\left\{x_{n}\right\}$ such that $x_{n_{k}} \rightarrow w \in C$, then $\left(x_{n_{k}}, w\right) \in E(G)$.

Then, $\left\{x_{n}\right\}$ converges strongly to $w=P_{F(\tau)} x_{0}$.

Proof. We split the proof into five steps.

Step 1: Show that $P_{C_{n+1}} x_{0}$ is well-defined for every $x_{0} \in C$. We know that $F(T)$ is convex, if $F(T) \times$ $F(T) \subseteq E(G)$ for all $T \in \tau$; see Theorem 3.2 of Tiammee et al. [12]. This implies that $F(\tau)$ is convex. It follows now from the assumption that $F(\tau)$ is closed. This implies that $P_{F(\tau)} x_{0}$ is well-defined. We first show, by induction, that $F(\tau) \subset C_{n}$ for all $n \in \mathbb{N}$. It is obvious that $F(\tau) \subset C_{1}$. Assume that $F(\tau) \subset C_{k}$ for some $k \in \mathbb{N}$. Then, by the fact that $\left\{x_{n}\right\}$ dominates $p$ for all $p \in F(\tau)$, for $x \in F(\tau) \subset C_{k}$,

$$
\begin{aligned}
\left\|y_{k}-x\right\| & =\left\|\alpha_{k} x_{k}+\left(1-\alpha_{k}\right) T_{k} x_{k}-x\right\| \\
& \leq \alpha_{k}\left\|x_{k}-x\right\|+\left(1-\alpha_{k}\right)\left\|T_{k} x_{k}-x\right\| \\
& \leq \alpha_{k}\left\|x_{k}-x\right\|+\left(1-\alpha_{k}\right)\left\|x_{k}-x\right\| \\
& =\left\|x_{k}-x\right\|
\end{aligned}
$$

and hence $x \in C_{k+1}$. This implies that $F(\tau) \subset C_{n}$ for all $n \in \mathbb{N}$. Next, we show that $C_{n}$ is closed and convex for all $n \in \mathbb{N}$. By the condition of $C_{n}, C_{1}=C$ is closed and convex. Assume that $C_{k}$ is closed and convex for some $k \in \mathbb{N}$. For $z \in C_{k}$, from [6], we know that $\left\|y_{k}-z\right\| \leq\left\|x_{k}-z\right\|$ is equivalent to $\left\|y_{k}-x_{k}\right\|^{2}+2\left\langle y_{k}-x_{k}, x_{k}-z\right\rangle \geq 0$. Thus, $C_{k+1}$ is closed and convex. Then, for any $n \in \mathbb{N}, C_{n}$ is closed and convex. This implies that $\left\{x_{n}\right\}$ is well-defined.

Step 2: Show that $\lim _{n \rightarrow \infty}\left\|x_{n}-x_{0}\right\|$ exists. From $x_{n}=P_{C_{n}} x_{0}$, we have $\left\langle x_{0}-x_{n}, x_{n}-y\right\rangle \geq 0$ for all $y \in C_{n}$. As $F(\tau) \subset C_{n}$, we also have

$$
\left\langle x_{0}-x_{n}, x_{n}-p\right\rangle \geq 0 \text { for all } p \in F(\tau) \text { and } n \in \mathbb{N} \text {. }
$$

Thus, for $p \in F(\tau)$, we have

$$
0 \leq\left\langle x_{0}-x_{n}, x_{n}-p\right\rangle=\left\langle x_{0}-x_{n}, x_{n}-x_{0}+x_{0}-p\right\rangle \leq-\left\|x_{0}-x_{n}\right\|^{2}+\left\|x_{0}-x_{n}\right\|\left\|x_{0}-p\right\| .
$$

This implies that

$$
\left\|x_{0}-x_{n}\right\| \leq\left\|x_{0}-x\right\|
$$

for all $x \in F(\tau)$ and $n \in \mathbb{N}$. From $x_{n}=P_{C_{n}} x_{0}$ and $x_{n+1}=P_{C_{n+1}} x_{0} \in C_{n+1} \subset C_{n}$, we also have

$$
0 \leq\left\langle x_{0}-x_{n}, x_{n}-x_{n+1}\right\rangle
$$


From (5), we have, for $n \in \mathbb{N}$,

$$
\begin{aligned}
0 & \leq\left\langle x_{0}-x_{n}, x_{n}-x_{n+1}\right\rangle \\
& =\left\langle x_{0}-x_{n}, x_{n}-x_{0}+x_{0}-x_{n+1}\right\rangle \\
& =-\left\|x_{0}-x_{n}\right\|^{2}+\left\langle x_{0}-x_{n}, x_{0}-x_{n+1}\right\rangle \\
& \leq-\left\|x_{0}-x_{n}\right\|^{2}+\left\|x_{0}-x_{n}\right\|\left\|x_{0}-x_{n+1}\right\|
\end{aligned}
$$

Thus,

$$
\left\|x_{0}-x_{n}\right\| \leq\left\|x_{0}-x_{n+1}\right\|
$$

Since $\left\{\left\|x_{n}-x_{0}\right\|\right\}$ is bounded, $\lim _{n \rightarrow \infty}\left\|x_{n}-x_{0}\right\|$ exists.

Step 3: Show that $x_{n} \rightarrow w \in C$ as $n \rightarrow \infty$. For $m>n$, by the definition of $C$, we see that $x_{m}=P_{C_{m}} x_{0} \in$ $C_{m} \subset C_{n}$. Thus, we have

$$
\left\|x_{n}-x_{m}\right\|^{2} \leq\left\|x_{n}-x_{0}\right\|^{2}-\left\|x_{m}-x_{0}\right\|^{2}
$$

Since $\left\{x_{n}\right\}$ is a Cauchy sequence, there exists $w \in C$ such that $x_{n} \rightarrow w$ as $n \rightarrow \infty$. This implies that $\left(x_{n}, w\right) \in E(G)$ by condition (ii).

Step 4: Show that $w \in F(\tau)$. From Step 3, we have that

$$
\lim _{n \rightarrow \infty}\left\|x_{n}-x_{n+1}\right\|=0 .
$$

On the other hand, $x_{n+1} \in C_{n+1} \subset C_{n}$ implies that

$$
\left\|y_{n}-x_{n+1}\right\| \leq\left\|x_{n}-x_{n+1}\right\|
$$

Furthermore, we have

$$
\begin{aligned}
\left\|y_{n}-x_{n}\right\| & =\left\|\alpha_{n} x_{n}+\left(1-\alpha_{n}\right) T_{n} x_{n}-x_{n}\right\| \\
& =\left(1-\alpha_{n}\right)\left\|T_{n} x_{n}-x_{n}\right\| .
\end{aligned}
$$

From (6), we obtain

$$
\begin{aligned}
\left\|T_{n} x_{n}-x_{n}\right\| & =\frac{1}{1-\alpha_{n}}\left\|y_{n}-x_{n}\right\| \\
& \leq \frac{1}{1-a}\left\|y_{n}-x_{n}\right\| \\
& =\frac{1}{1-a}\left\|y_{n}-x_{n+1}+x_{n+1}-x_{n}\right\| \\
& \leq \frac{2}{1-a}\left\|x_{n}-x_{n+1}\right\| .
\end{aligned}
$$

Hence, by (7), we have $\left\|T_{n} x_{n}-x_{n}\right\| \rightarrow 0$. Since $\left\{T_{n}\right\}$ satisfies the NST-condition with respect to $\tau$, we get

$$
\left\|T x_{n}-x_{n}\right\| \rightarrow 0 \text { for all } T \in \tau
$$

From Step 3, we know that $x_{n} \rightarrow w \in C$. From (ii) and (8), we obtain $w \in F(\tau)$ by Lemma 6. Step 5: Show that $w=P_{F(\tau)} x_{0}$. Since $x_{n}=P_{C_{n}} x_{0}$ and $F(\tau) \subset C_{n}$, we obtain

$$
\left\langle x_{0}-x_{n}, x_{n}-z\right\rangle \geq 0, \forall z \in F(\tau) \text {. }
$$


By taking the limit in (9), we obtain

$$
\left\langle x_{0}-w, w-z\right\rangle \geq 0, \forall z \in F(\tau) .
$$

This shows that $w=P_{F(\tau)} x_{0}$.

We next give some examples of a family of $G$-nonexpansive mappings $\left\{T_{n}\right\}$, which satisfies the NST-condition.

Example 1. Let $T \in \tau$. Define $T_{n}=\beta_{n} I+\left(1-\beta_{n}\right) T$, where $0<b \leq \beta_{n} \leq c<1$ for all $n \in \mathbb{N}$. Then, $\left\{T_{n}\right\}$ is a family of G-nonexpansive mappings and satisfies the NST-condition.

Proof. We first prove that $T_{n}=\beta_{n} I+\left(1-\beta_{n}\right) T$ is $G$-nonexpansive for all $n \in \mathbb{N}$.

Since $E(G)$ is convex and $(T x, T y) \in E(G)$ for all $(x, y) \in E(G)$, then

$$
\left(T_{n} x, T_{n} y\right)=\left(\beta_{n} x+\left(1-\beta_{n}\right) T x, \beta_{n} y+\left(1-\beta_{n}\right) T y\right) \in E(G) .
$$

Furthermore, we have

$$
\begin{aligned}
\left\|T_{n} x-T_{n} y\right\| & =\left\|\beta_{n} x+\left(1-\beta_{n}\right) T x-\beta_{n} y-\left(1-\beta_{n}\right) T y\right\| \\
& =\left\|\beta_{n}(x-y)+\left(1-\beta_{n}\right)(T x-T y)\right\| \\
& \leq \beta_{n}\|x-y\|+\left(1-\beta_{n}\right)\|T x-T y\| \\
& \leq \beta_{n}\|x-y\|+\left(1-\beta_{n}\right)\|x-y\| \\
& =\|x-y\| .
\end{aligned}
$$

Hence, $T_{n}=\beta_{n} I+\left(1-\beta_{n}\right) T$ is $G$-nonexpansive for all $n \in \mathbb{N}$.

Next, we show that $\left\{T_{n}\right\}$ satisfies the NST-condition with respect to T. First, we show that $F(\tau)=\bigcap_{n=1}^{\infty} F\left(T_{n}\right)$. It is obvious that $F(\tau) \subset \bigcap_{n=1}^{\infty} F\left(T_{n}\right)$. On the other hand, let $p \in \bigcap_{n=1}^{\infty} F\left(T_{n}\right)$. Then, we have

$$
p=T_{n} p=\beta_{n} p+\left(1-\beta_{n}\right) T p=\beta_{n} p+T p-\beta_{n} T p=\beta_{n}(p-T p)+T p .
$$

Then, $p-T p=\beta_{n}(p-T p)$, which implies that $\left(1-\beta_{n}\right)\|p-T p\|=0$. Hence, $p \in F(\tau)$ that is $\bigcap_{n=1}^{\infty} F\left(T_{n}\right) \subset F(\tau)$. This shows that $F(\tau)=\bigcap_{n=1}^{\infty} F\left(T_{n}\right)$. Let $\left\{x_{n}\right\}$ be a sequence in $C$ such that $\lim _{n \rightarrow \infty}\left\|T_{n} x_{n}-x_{n}\right\|=0$; we have $\left\|x_{n}-T_{n} x_{n}\right\|=\left\|x_{n}-\left(\beta_{n} x_{n}+\left(1-\beta_{n}\right) T x_{n}\right)\right\|=\left(1-\beta_{n}\right)\left\|x_{n}-T x_{n}\right\|$. Since $\lim _{n \rightarrow \infty}\left\|x_{n}-T_{n} x_{n}\right\|=0$, then

$$
\lim _{n \rightarrow \infty}\left\|x_{n}-T x_{n}\right\|=0
$$

From (11) and (12), we get that $\left\{T_{n}\right\}$ satisfies the NST-condition with respect to $\tau$.

Example 2. Let $T, S \in \tau$. Define $T_{n}=\beta_{n} I+\gamma_{n} S+\left(1-\beta_{n}-\gamma_{n}\right) T$, where $0<b \leq \beta_{n}<1,0<c \leq$ $\gamma_{n}<1$ and $0<\beta_{n}+\gamma_{n} \leq d<1$ for all $n \in \mathbb{N}$. If $S z=T z$ and $(x, z) \in E(G)$ for all $z \in \bigcap_{n=1}^{\infty} F\left(T_{n}\right)$ and $x \in C$, then $\left\{T_{n}\right\}$ is a family of G-nonexpansive mappings and satisfies the NST-condition.

Proof. We first prove that $T_{n}=\beta_{n} I+\gamma_{n} S+\left(1-\beta_{n}-\gamma_{n}\right) T$ is $G$-nonexpansive for all $n \in \mathbb{N}$. Since $E(G)$ is convex and $(S x, S y),(T x, T y) \in E(G)$ for all $(x, y) \in E(G)$, then

$$
\begin{aligned}
\left(T_{n} x, T_{n} y\right) & =\left(\beta_{n} x+\gamma_{n} S x+\left(1-\beta_{n}-\gamma_{n}\right) T x, \beta_{n} y+\gamma_{n} S y+\left(1-\beta_{n}-\gamma_{n}\right) T y\right) \\
& \in E(G) .
\end{aligned}
$$


Furthermore, we have

$$
\begin{aligned}
\left\|T_{n} x-T_{n} y\right\| & \left.=\| \beta_{n} x+\gamma_{n} S x+\left(1-\beta_{n}-\gamma_{n}\right) T x-\beta_{n} y-\gamma_{n} S y-\left(1-\beta_{n}-\gamma_{n}\right) T y\right) \| \\
& =\left\|\beta_{n}(x-y)+\gamma_{n}(S x-S y)+\left(1-\beta_{n}-\gamma_{n}\right)(T x-T y)\right\| \\
& \leq \beta_{n}\|x-y\|+\gamma_{n}\|S x-S y\|+\left(1-\beta_{n}-\gamma_{n}\right)\|T x-T y\| \\
& \leq\|x-y\| .
\end{aligned}
$$

From (13) and (14), we have that $T_{n}$ is $G$-nonexpansive for all $n \in \mathbb{N}$. Next, we show that $\left\{T_{n}\right\}$ satisfies the NST-condition with respect to $\tau$. It is clear that $F(\tau) \subset \bigcap_{n=1}^{\infty} F\left(T_{n}\right)$. On the other hand, we let $p \in \bigcap_{n=1}^{\infty} F\left(T_{n}\right)$.

Consider

$$
\begin{aligned}
\|p-T p\| & \leq\left\|p-T_{n} p\right\|+\left\|T_{n} p-T p\right\| \\
& =\left\|\beta_{n} p+\gamma_{n} S p+\left(1-\beta_{n}-\gamma_{n}\right) T p-T p\right\| \\
& =\left\|\beta_{n}(p-T p)+\gamma_{n}(S p-T p)\right\| \\
& \leq \beta_{n}\|p-T p\|+\gamma_{n}\|S p-T p\| .
\end{aligned}
$$

By our assumption, we obtain $\|p-T p\|=0$. Hence, $p=T p=S p$. Therefore, $F(\tau)=\bigcap_{n=1}^{\infty} F\left(T_{n}\right)$. Next, we let $\left\{x_{n}\right\}$ be a sequence in $C$ such that $\lim _{n \rightarrow \infty}\left\|x_{n}-T_{n} x_{n}\right\|=0$ and $p \in F(\tau)$. We shall show that $\lim _{n \rightarrow \infty}\left\|T x_{n}-x_{n}\right\|=\lim _{n \rightarrow \infty}\left\|S x_{n}-x_{n}\right\|=0$. Since $\left(x_{n}, p\right) \in E(G)$ for all $n \in \mathbb{N}$, we have

$$
\begin{aligned}
\left\|T_{n} x_{n}-p\right\|^{2}= & \left\|\beta_{n} x_{n}+\gamma_{n} S x_{n}+\left(1-\beta_{n}-\gamma_{n}\right) T x_{n}-p\right\|^{2} \\
= & \beta_{n}\left\|x_{n}-p\right\|^{2}+\gamma_{n}\left\|S x_{n}-p\right\|^{2} \\
& +\left(1-\beta_{n}-\gamma_{n}\right)\left\|T x_{n}-p\right\|^{2} \\
& -\beta_{n} \gamma_{n}\left\|S x_{n}-x_{n}\right\|^{2}-\beta_{n}\left(1-\beta_{n}-\gamma_{n}\right)\left\|T x_{n}-x_{n}\right\|^{2} .
\end{aligned}
$$

Thus,

$$
\beta_{n}\left(1-\beta_{n}-\gamma_{n}\right)\left\|T x_{n}-x_{n}\right\|^{2}+\beta_{n} \gamma_{n}\left\|S x_{n}-x_{n}\right\|^{2} \leq\left\|x_{n}-p\right\|^{2}-\left\|T_{n} x_{n}-p\right\|^{2} .
$$

Since $\left\|x_{n}-T_{n} x_{n}\right\| \rightarrow 0$ as $n \rightarrow \infty$, by our assumptions, we have $\left\|T x_{n}-x_{n}\right\| \rightarrow 0$ and $\left\|S x_{n}-x_{n}\right\| \rightarrow 0$ as $n \rightarrow \infty$. Hence, $\left\{T_{n}\right\}$ satisfies the NST-condition with respect to $\tau=\{S, T\}$.

Example 3. Let $T, S \in \tau$. Define $T_{n}=\gamma_{n} I+\left(1-\gamma_{n}\right) S\left(\beta_{n} I+\left(1-\beta_{n}\right) T\right)$, where $0<b \leq \beta_{n} \leq c<1$ and $0<d \leq \gamma_{n} \leq e<1$. If $\left(p, x^{*}\right) \in E(G)$ for all $p \in \bigcap_{n=1}^{\infty} F\left(T_{n}\right), x^{*} \in F(\tau)$ and $(x, T x),\left(x, x^{*}\right) \in E(G)$ for all $x \in C$ and $x^{*} \in F(\tau)$, then $\left\{T_{n}\right\}$ is a family of G-nonexpansive mappings and satisfies the NST-condition.

Proof. We first prove that $T_{n}$ is $G$-nonexpansive for all $n \in \mathbb{N}$. Let $(x, y) \in E(G)$, and we see that $(T x, T y) \in E(G)$. Setting $U_{n}=\beta_{n}+\left(1-\beta_{n}\right) T$, by the convexity of $E(G)$, we have $\left(U_{n} x, U_{n} y\right)=$ $\left(\beta_{n} x+\left(1-\beta_{n}\right) T x, \beta_{n} y+\left(1-\beta_{n}\right) T y\right) \in E(G)$. This implies that $\left(S\left(\beta_{n} x+\left(1-\beta_{n}\right) T x\right), S\left(\beta_{n} y+(1-\right.\right.$ $\left.\left.\left.\beta_{n}\right) T y\right)\right) \in E(G)$. Again by the convexity of $E(G)$, we have

$$
\left(T_{n} x, T_{n} y\right)=\left(\gamma_{n} x+\left(1-\gamma_{n}\right) S\left(\beta_{n} x+\left(1-\beta_{n}\right) T x\right), \gamma_{n} y+\left(1-\gamma_{n}\right) S\left(\beta_{n} y+\left(1-\beta_{n}\right) T y\right)\right) \in E(G) .
$$

Then, we have

$$
\begin{aligned}
\left\|U_{n} x-U_{n} y\right\| & =\left\|\beta_{n} x+\left(1-\beta_{n}\right) T x-\beta_{n} y-\left(1-\beta_{n}\right) T y\right\| \\
& \leq \beta_{n}\|x-y\|+\left(1-\beta_{n}\right)\|T x-T y\| \\
& \leq\|x-y\|,
\end{aligned}
$$


and hence

$$
\begin{aligned}
\left\|T_{n} x-T_{n} y\right\| & =\left\|\gamma_{n} x+\left(1-\gamma_{n}\right) S U_{n} x-\gamma_{n} y-\left(1-\gamma_{n}\right) S U_{n} y\right\| \\
& =\left\|\gamma_{n}(x-y)+\left(1-\gamma_{n}\right)\left(S U_{n} x-S U_{n} y\right)\right\| \\
& \leq \gamma_{n}\|x-y\|+\left(1-\gamma_{n}\right)\left\|S U_{n} x-S U_{n} y\right\| \\
& \leq \gamma_{n}\|x-y\|+\left(1-\gamma_{n}\right)\left\|U_{n} x-U_{n} y\right\| \\
& \leq \gamma_{n}\|x-y\|+\left(1-\gamma_{n}\right)\|x-y\| \\
& =\|x-y\| .
\end{aligned}
$$

Hence, $T_{n}$ is $G$-nonexpansive for all $n \in \mathbb{N}$. Next, we show that $\left\{T_{n}\right\}$ satisfies the NST-condition with respect to $\tau$. It is obvious that $F(\tau) \subset \bigcap_{n=1}^{\infty} F\left(T_{n}\right)$. Thus, it is enough to show that $\bigcap_{n=1}^{\infty} F\left(T_{n}\right) \subset F(\tau)$. Let $x^{*} \in F(\tau), p \in \bigcap_{n=1}^{\infty} F\left(T_{n}\right)$ and $\left(p, x^{*}\right) \in E(G)$. Then, we have $\left(U_{n} p, x^{*}\right) \in E(G)$. It follows that

$$
\begin{aligned}
\left\|p-x^{*}\right\| & =\left\|T_{n} p-x^{*}\right\| \\
& =\left\|r_{n} p+\left(1-\gamma_{n}\right) S U_{n} p-x^{*}\right\| \\
& \leq \gamma_{n}\left\|p-x^{*}\right\|+\left(1-\gamma_{n}\right)\left\|S U_{n} p-S x^{*}\right\| \\
& \leq \gamma_{n}\left\|p-x^{*}\right\|+\left(1-\gamma_{n}\right)\left\|U_{n} p-x^{*}\right\| \\
& \leq \gamma_{n}\left\|p-x^{*}\right\|+\left(1-\gamma_{n}\right)\left\|\beta_{n} p+\left(1-\beta_{n}\right) T p-x^{*}\right\| \\
& \leq \gamma_{n}\left\|p-x^{*}\right\|+\left(1-\gamma_{n}\right)\left(\beta_{n}\left\|p-x^{*}\right\|+\left(1-\beta_{n}\right)\left\|T p-T x^{*}\right\|\right) \\
& \leq\left\|p-x^{*}\right\| .
\end{aligned}
$$

This implies that $\left\|p-x^{*}\right\|=\gamma_{n}\left\|p-x^{*}\right\|+\left(1-\gamma_{n}\right)\left\|U_{n} p-x^{*}\right\|$. Then, we have

$$
\begin{aligned}
\left\|p-x^{*}\right\| & =\left\|U_{n} p-x^{*}\right\| \\
& =\left\|T p-x^{*}\right\| \\
& =\left\|\beta_{n} p+\left(1-\beta_{n}\right) T p-x^{*}\right\| \\
& =\left\|\beta_{n}\left(p-x^{*}\right)+\left(1-\beta_{n}\right)\left(T p-x^{*}\right)\right\| .
\end{aligned}
$$

From Lemma 5, $T p=p$. Consider

$$
\begin{aligned}
\|p-S p\| & \leq\left\|p-T_{n} p\right\|+\left\|T_{n} p-S p\right\| \\
& =\left\|\gamma_{n} p+\left(1-\gamma_{n}\right) S U_{n} p-S p\right\| \\
& \leq \gamma_{n}\|p-S p\|+\left(1-\gamma_{n}\right)\left\|S U_{n} p-S p\right\| \\
& \leq \gamma_{n}\|p-S p\|+\left(1-\gamma_{n}\right)\left\|U_{n} p-p\right\| . \\
& \leq \gamma_{n}\|p-S p\|+\left(1-\gamma_{n}\right)\left(1-\beta_{n}\right)\|T p-p\| .
\end{aligned}
$$

This implies that $S p=p$. This shows that $F(\tau)=\bigcap_{n=1}^{\infty} F\left(\tau_{n}\right)$.

Let $\left\{x_{n}\right\}$ be a sequence in $C$ such that $\lim _{n \rightarrow 0}\left\|T_{n} x_{n}-x_{n}\right\|=0$. Since $\left\{x_{n}\right\}$ dominates $p$, then $\left(U_{n} x_{n}, p\right)=\left(\beta_{n} x_{n}+\left(1-\beta_{n}\right) T x_{n}, p\right) \in E(G)$. It follows that

$$
\begin{aligned}
\left\|T_{n} x_{n}-p\right\|^{2}= & \left\|\gamma_{n} x_{n}-\left(1-\gamma_{n}\right) S U_{n} x_{n}-p\right\|^{2} \\
\leq & \gamma_{n}\left\|x_{n}-p\right\|^{2}+\left(1-\gamma_{n}\right)\left\|S U_{n} x_{n}-p\right\|^{2} \\
\leq & \gamma_{n}\left\|x_{n}-p\right\|^{2}+\left(1-\gamma_{n}\right)\left\|U_{n} x_{n}-p\right\|^{2} \\
= & \gamma_{n}\left\|x_{n}-p\right\|^{2}+\left(1-\gamma_{n}\right)\left(\beta_{n}\left\|x_{n}-p\right\|^{2}+\left(1-\beta_{n}\right)\left\|T x_{n}-p\right\|^{2}\right. \\
& \left.-\beta_{n}\left(1-\beta_{n}\right)\left\|T x_{n}-x_{n}\right\|^{2}\right) \\
\leq & \left\|x_{n}-p\right\|^{2}-\left(1-\gamma_{n}\right) \beta_{n}\left(1-\beta_{n}\right)\left\|T x_{n}-x_{n}\right\|^{2} .
\end{aligned}
$$


This implies that

$$
\left(1-\gamma_{n}\right) \beta_{n}\left(1-\beta_{n}\right)\left\|T x_{n}-x_{n}\right\|^{2} \leq\left\|x_{n}-p\right\|^{2}-\left\|T_{n} x_{n}-p\right\|^{2} .
$$

By our assumptions, we obtain

$$
\lim _{n \rightarrow \infty}\left\|T x_{n}-x_{n}\right\|=0
$$

It follows that

$$
\left\|U_{n} x_{n}-x_{n}\right\|=\left(1-\beta_{n}\right)\left\|T x_{n}-x_{n}\right\| \rightarrow 0,
$$

as $n \rightarrow \infty$. Since $\left(U_{n} x_{n}, p\right) \in E(G)$, it follows from (16) that

$$
\begin{aligned}
\left\|T_{n} x_{n}-p\right\|^{2} & =\left\|\gamma_{n} x_{n}-\left(1-\gamma_{n}\right) S U_{n} x_{n}-p\right\|^{2} \\
& =\gamma_{n}\left\|x_{n}-p\right\|^{2}+\left(1-\gamma_{n}\right)\left\|S U_{n} x_{n}-p\right\|^{2}-\gamma_{n}\left(1-\gamma_{n}\right)\left\|S U_{n} x_{n}-x_{n}\right\|^{2} \\
& \leq \gamma_{n}\left\|x_{n}-p\right\|^{2}+\left(1-\gamma_{n}\right)\left\|U_{n} x_{n}-p\right\|^{2}-\gamma_{n}\left(1-\gamma_{n}\right)\left\|S U_{n} x_{n}-x_{n}\right\|^{2} \\
& \leq\left\|x_{n}-p\right\|^{2}-\gamma_{n}\left(1-\gamma_{n}\right)\left\|S U_{n} x_{n}-x_{n}\right\|^{2} .
\end{aligned}
$$

This implies that

$$
\gamma_{n}\left(1-\gamma_{n}\right)\left\|S U_{n} x_{n}-x_{n}\right\|^{2} \leq\left\|x_{n}-p\right\|^{2}-\left\|T_{n} x_{n}-p\right\|^{2} .
$$

By our assumptions and (20), we have

$$
\lim _{n \rightarrow \infty}\left\|S U_{n} x_{n}-x_{n}\right\|=0 .
$$

It follows from (21) and (24) that

$$
\begin{aligned}
\left\|T_{n} x_{n}-S x_{n}\right\| & =\left\|\gamma_{n} x_{n}+\left(1-\gamma_{n}\right) S U_{n} x_{n}-S x_{n}\right\| \\
& =\left\|\gamma_{n}\left(x_{n}-S x_{n}\right)+\left(1-\gamma_{n}\right)\left(S U_{n} x_{n}-S x_{n}\right)\right\| \\
& \leq \gamma_{n}\left\|x_{n}-S x_{n}\right\|+\left(1-\gamma_{n}\right)\left\|S U_{n} x_{n}-S x_{n}\right\| \\
& \leq \gamma_{n}\left(\left\|x_{n}-S U_{n} x_{n}\right\|+\left\|S U_{n} x_{n}-S x_{n}\right\|\right)+\left(1-\gamma_{n}\right)\left\|U_{n} x_{n}-x_{n}\right\| \\
& \leq \gamma_{n}\left\|x_{n}-S U_{n} x_{n}\right\|+\gamma_{n}\left\|U_{n} x_{n}-x_{n}\right\|+\left(1-\gamma_{n}\right)\left\|U_{n} x_{n}-x_{n}\right\| \\
& =\gamma_{n}\left\|x_{n}-S U_{n} x_{n}\right\|+\left\|U_{n} x_{n}-x_{n}\right\| \rightarrow 0,
\end{aligned}
$$

as $n \rightarrow \infty$. This implies that $\left\|S x_{n}-x_{n}\right\| \leq\left\|S x_{n}-T_{n} x_{n}\right\|+\left\|T_{n} x_{n}-x_{n}\right\| \rightarrow 0$, as $n \rightarrow \infty$. Hence, $\left\{T_{n}\right\}$ satisfies the NST-condition with respect to $\tau=\{S, T\}$.

\section{Examples and Numerical Results}

In this section, we provide some numerical examples to support our obtained result.

Example 4. Let $H=\mathbb{R}$ and $C=[0,2]$. Assume that $(x, y) \in E(G)$ if and only if $0.4 \leq x, y \leq 1.6$ or $x=y$, where $x, y \in \mathbb{R}$. Define mappings $T, S: C \rightarrow C$ by

$$
\begin{aligned}
T x & =\sin \left(\frac{\pi}{2}\right) \cos (\tan (x-1)), \\
S x & =\frac{\ln x}{3}+1,
\end{aligned}
$$

for all $x \in C$. It is easy to check that $T$ and $S$ are $G$-nonexpansive such that $F(S)=F(T)=\{1\}$. We have that $T$ is not nonexpansive since for $x=1.6$ and $y=1.8$, then $\|T x-T y\|>0.21>\|x-y\|$. We also have that $S$ is not nonexpansive since, for $x=0.1$ and $y=0.6$, then $\|S x-S y\|>0.58>\|x-y\|$. 
We use the mappings in Example 4 and choose $x_{0}=0.4$. By computing, we obtain the sequences generated in Theorem 3 by using the mapping $T_{n}$ which, generated from Examples $1-3$, converges to 1. We next show the following error plots of $\left\|x_{n+1}-x_{n}\right\|$ :

(1) Choose $\alpha_{n}=\frac{n}{5 n+2}$ and $\beta_{n}=\frac{n}{4 n+3}$; then, the sequences $\left\{\alpha_{n}\right\}$ and $\left\{\beta_{n}\right\}$ satisfy the conditions in Theorem 3 and Example 1.

(2) Choose $\alpha_{n}=\frac{n}{5 n+2}, \beta_{n}=\frac{n}{4 n+3}$ and $\gamma_{n}=\frac{n}{2 n+1}$; then, the sequences $\left\{\alpha_{n}\right\},\left\{\beta_{n}\right\}$ and $\left\{\gamma_{n}\right\}$ satisfy the conditions in Theorem 3 and Examples 2-3.

Example 5. Let $H=\mathbb{R}^{3}$ and $C=[0, \infty)^{3}$. Assume that $(x, y) \in E(G)$ if and only if $0.4 \leq x_{i}, y_{i} \leq 1.6$ or $x_{i}=y_{i}$ for all $i=1,2,3$, where $x=\left(x_{1}, x_{2}, x_{3}\right), y=\left(y_{1}, y_{2}, y_{3}\right) \in \mathbb{R}^{3}$. Define mappings $T, S: C \rightarrow C$ by

$$
\begin{gathered}
T x=\left(\sin \left(\frac{\pi}{2}\right) \cos \left(\tan \left(x_{1}-1\right)\right), \tan \frac{\left(x_{2}-1\right)}{\sqrt{7.45}}+1,1\right), \\
S x=\left(1,1, \frac{\ln x_{3}}{3}+1\right)
\end{gathered}
$$

for any $x=\left(x_{1}, x_{2}, x_{3}\right) \in C$. It is easy to check that $T$ and $S$ are $G$-nonexpansive such that $F(S)=F(T)=$ $\{(1,1,1)\}$. On the other hand, $T$ is not nonexpansive since, for $x=(1.6,2,1)$ and $y=(1.8,2,1)$, then $\|T x-T y\|>0.21>\|x-y\|$. We also have that $S$ is not nonexpansive since, for $x=(2,1,0.1)$ and $y=(2,1,0.6)$, then $\|S x-S y\|>0.58>\|x-y\|$.

We use the mappings in Example 5 and choose $x_{0}=(0.4,0.4,0.5)$. By computing, we obtain the sequences $\left\{x_{n}\right\}$ generated in Theorem 3 by using the mapping $T_{n}$, which generated from Examples $1-3$, converge to $(1,1,1)$. We next show the following error plots of $\left\|x_{n+1}-x_{n}\right\|$.

(1) Choose $\alpha_{n}=\frac{n}{5 n+2}$ and $\beta_{n}=\frac{n}{4 n+3}$; then, the sequences $\left\{\alpha_{n}\right\}$ and $\left\{\beta_{n}\right\}$ satisfy the conditions in Theorem 3 and Example 1.

(2) Choose $\alpha_{n}=\frac{n}{5 n+2}, \beta_{n}=\frac{n}{4 n+3}$ and $\gamma_{n}=\frac{n}{2 n+1}$; then, the sequences $\left\{\alpha_{n}\right\},\left\{\beta_{n}\right\}$ and $\left\{\gamma_{n}\right\}$ satisfy the conditions in Theorem 3 and Examples 2-3.

Remark 1. According to the investigation of our numerical results under the same conditions, we see that the sequence in Theorem 3, which generated by using the mapping $T_{n}$ in Example 2, converges faster than the sequence of Example 3.

\section{Conclusions}

In this paper, we introduce the iterative scheme for approximating a common fixed point of a countable family of G-nonexpansive mappings by modifying the shrinking projection method. We then prove strong convergence theorems in a Hilbert space with a directed graph under some suitable conditions. We give some examples of some families of $G$-nonexpansive mappings $\left\{T_{n}\right\}$ that satisfy the NST-condition with respect to its $\tau$ (see in Examples 1-3). Finally, we give some numerical experiments for supporting our main results and compare the rate of convergence of some examples under the same conditions (see in Examples 4 and 5 and Figures 1-4). 


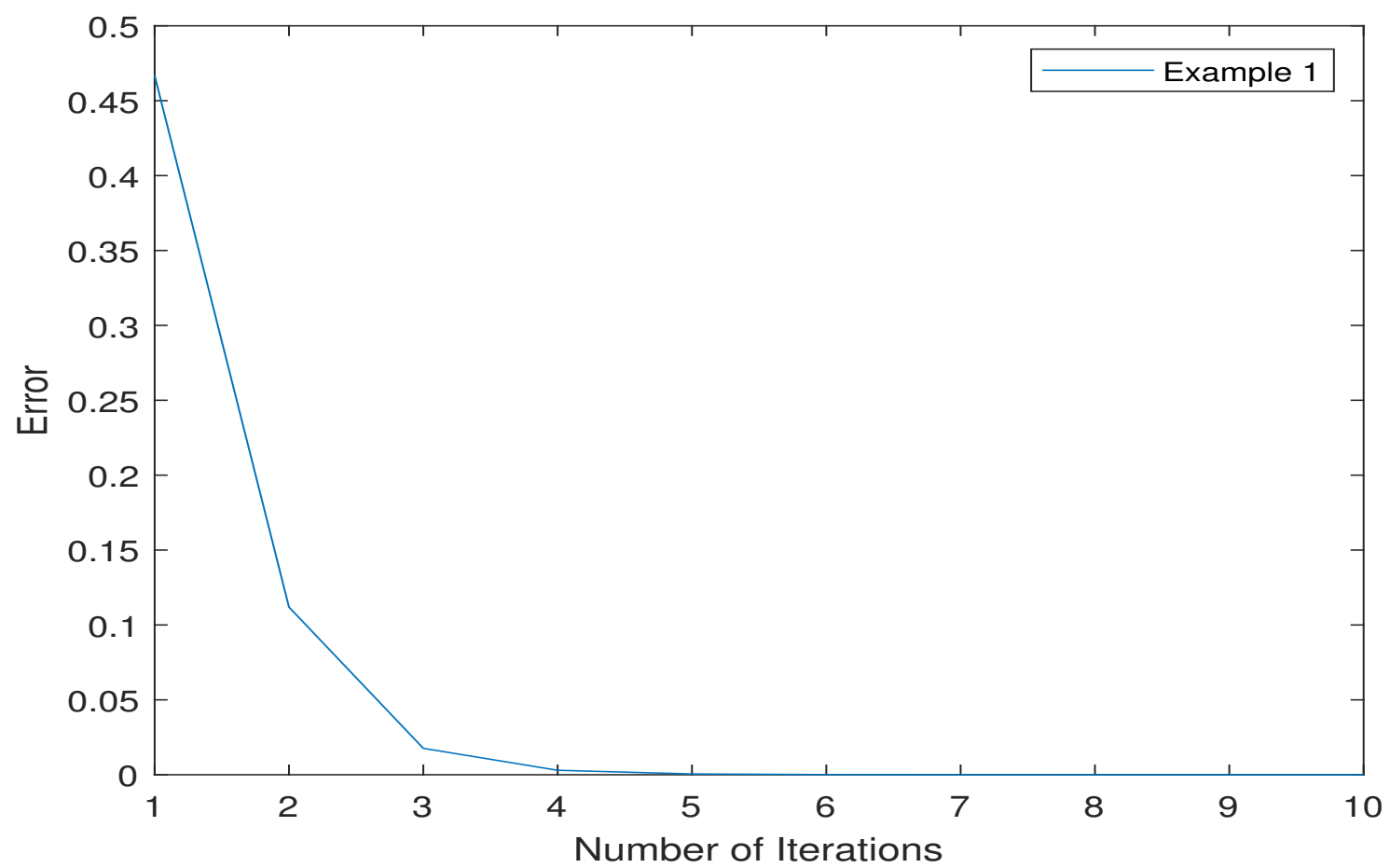

Figure 1. Error plots of the sequence $\left\{x_{n}\right\}$ in Theorem 3 by using the mapping $T_{n}$ in Example 1.

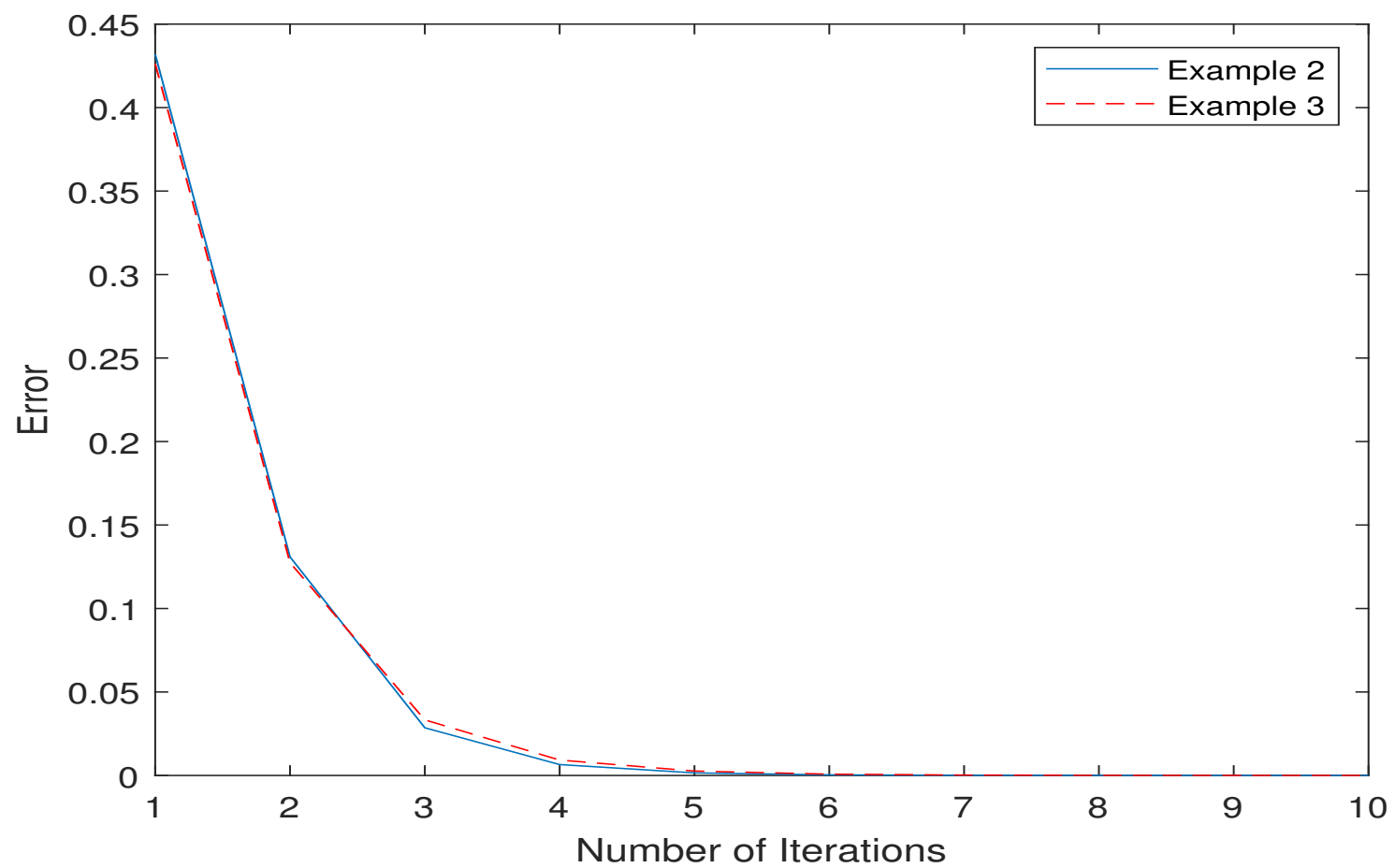

Figure 2. Error plots of the sequence $\left\{x_{n}\right\}$ in Theorem 3 by using the mapping $T_{n}$ in Examples 2 and 3. 


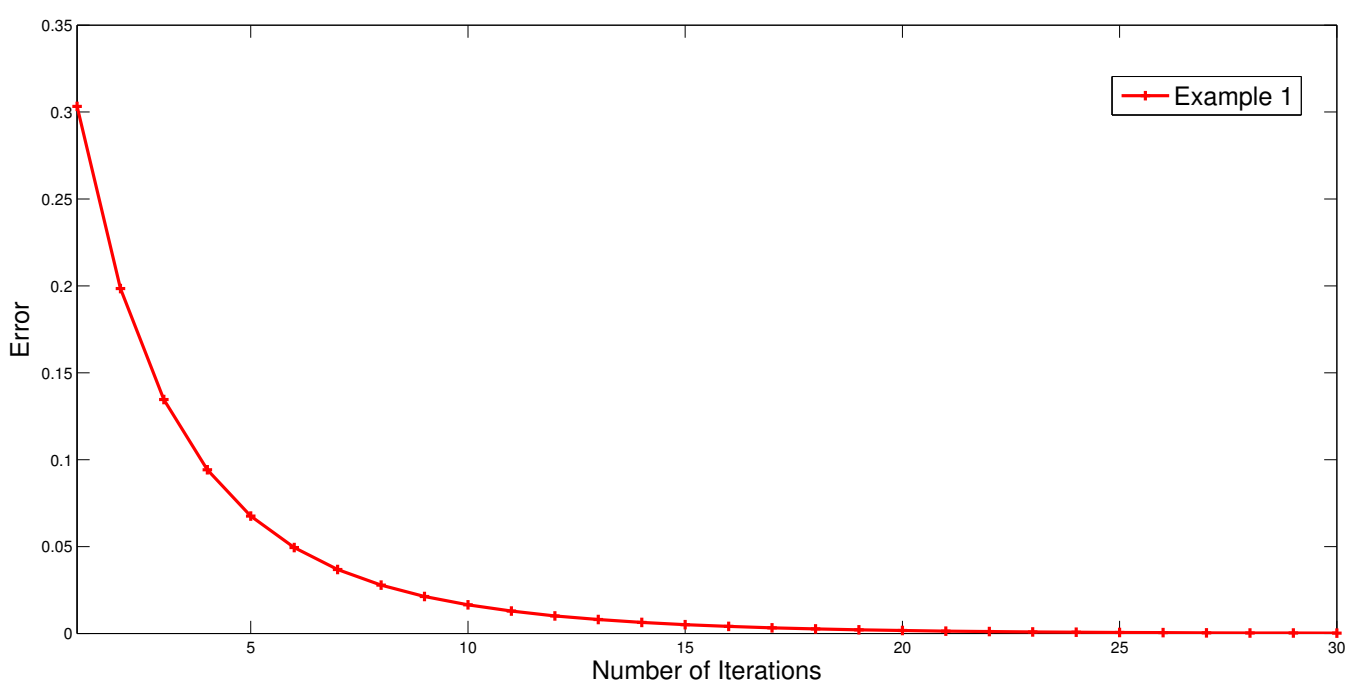

Figure 3. Error plots of the sequence $\left\{x_{n}\right\}$ in Theorem 3 by using the mapping $T_{n}$ in Example 1.

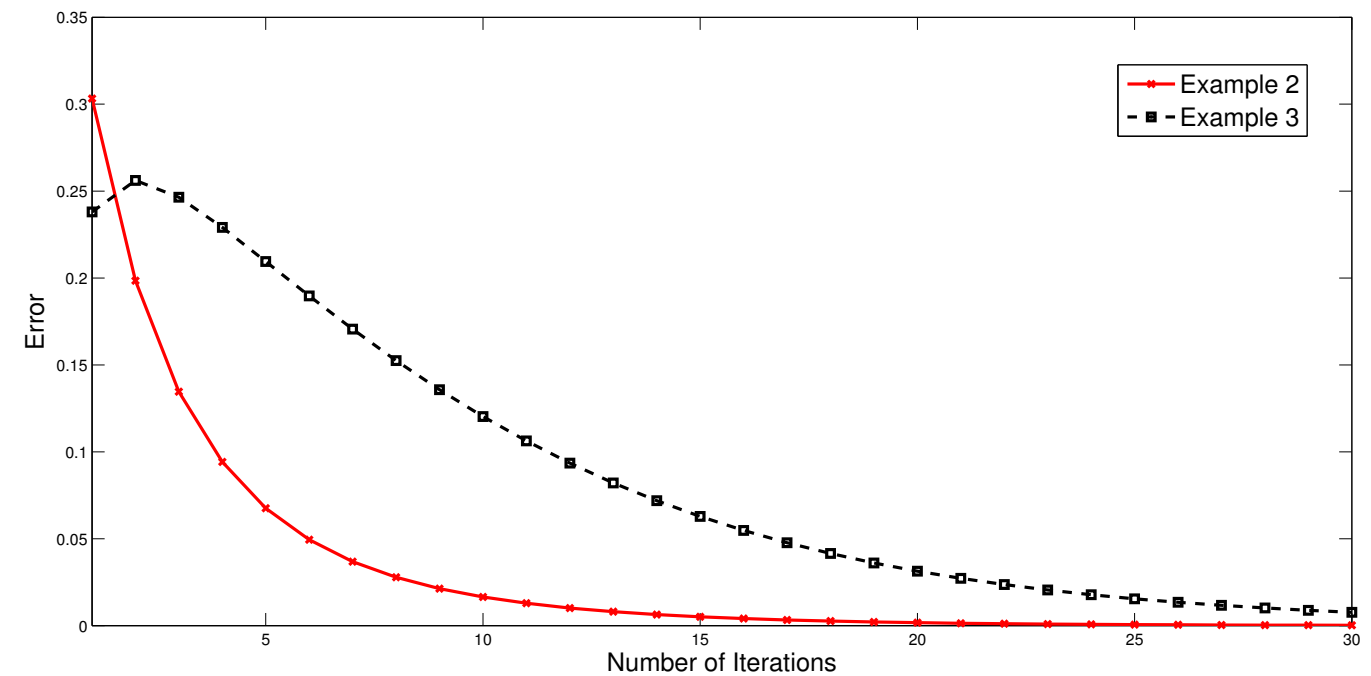

Figure 4. Error plots of the sequence $\left\{x_{n}\right\}$ in Theorem 3 by using the mapping $T_{n}$ in Examples 2 and 3.

Author Contributions: Funding acquisition and Supervision, S.S.; Writing—review \& editing and Software, M.D. and W.C.

Funding: This research was funded by Chiang Mai University.

Acknowledgments: The first author thanks Chiang Mai University for financial support.

Conflicts of Interest: The authors declare no conflict of interest.

\section{References}

1. Halpern, B. Fixed points of nonexpanding maps. Bull. Am. Math. Soc. 1967, 73, 957-961. [CrossRef]

2. Mann, W.R. Mean value methods in iteration. Proc. Am. Math. Soc. 1953, 4, 506-510. [CrossRef]

3. Wittmann, R. Approximation of fixed points of nonexpansive mappings. Arch. Math. 1992, 58, $486-491$. [CrossRef]

4. Emmanuele, G. Convergence of the Mann-Ishikawa iterative process for nonexpansive mappings. Nonlinear Anal. Theory Methods Appl. 1982, 6, 1135-1141. [CrossRef] 
5. Hicks, T.L.; Kubicek, J.D. On the Mann iteration process in a Hilbert space. J. Math. Anal. Appl. 1977, 59, 498-504. [CrossRef]

6. Song, Y.; Promluang, K.; Kumam, P.; Cho, Y.J. Some convergence theorems o fthe Mann iteration for monotone $\alpha$-nonexpansive mappings. Appl. Math. Comp. 2016, 287, 74-82. [CrossRef]

7. Nakajo, K.; Shimoji, K.; Takahashi, W. Strong convergence theorems by the hybrid method for families of mappings in Hilbert spaces. Taiwan. J. Math. 2006, 10, 339-360. [CrossRef]

8. Takahashi, W.; Takeuchi, Y.; Kubota, R. Strong convergence theorems by hybrid methods for families of nonexpansive mappings in Hilbert spaces. J. Math. Anal. Appl. 2008, 341, 276-286. [CrossRef]

9. Boung, N.; Lang, N.D. Shrinking hybrid descent-like methods for noexpansive mappings and semigroups. Nonlinear Funct. Anal. Appl. 2011, 16, 331-339.

10. Kimura, Y. Shrinking projection methods for a family of maximal monotone operators. Nonlinear Funct. Anal. Appl. 2011, 16, 61.

11. Jachymski, J. The contraction principle for mappings on a metric space with a graph. Proc. Am. Math. Soc. 2008, 136, 1359-1373. [CrossRef]

12. Tiammee, J.; Kaewkhao, A.; Suantai, S. On Browder's convergence theorem and Halpern iteration process for G-nonexpansive mappings in Hilbert spaces endowed with graphs. Fixed Point Theory Appl. 2015, 2015, 187. [CrossRef]

13. Alfuraidan, M.R. Fixed points of monotone nonexpansive mappings with a graph. Fixed Point Theory Appl. 2015, 2015, 49. [CrossRef]

14. Suparatulatorn, R.; Cholamjiak, W.; Suantai, S. Hybrid methods for a finite family of G-nonexpansive mappings in Hilbert spaces endowed with graphs. AKCE Int. J. Graphs Comb. 2017, 14, 101-111. [CrossRef]

15. Tripak, O. Common fixed points of G-nonexpansive mappings on Banach spaces with a graph. Fixed Point Theory Appl. 2016. [CrossRef]

16. Marino, G.; Xu, H.K. Weak and strong convergence theorems for strict pseudo-contractions in Hilbert spaces. J. Math. Anal. Appl. 2007, 329, 336-346. [CrossRef]

17. Martinez-Yanes, C.; Xu, H.-K. Strong convergence of CQ method for fixed point iteration processes. Nonlinear Anal. 2006, 64, 2400-2411. [CrossRef]

18. Nakajo, K.; Takahasi, W. Strongly convergence theorems for nonexpansive mappings and nonexpansive semigroups. J. Math. Anal Appl. 2003, 279, 372-379. [CrossRef]

19. Chidume, C.E.; Ezeora, J.N. Krasnoselkii-type algorithm for family of multi-valued strictly pseudo-contractive mappings. Fixed Point Theory Appl. 2014, 2014, 111. [CrossRef]

20. Takahashi, W. Nonlinear Function Analysis, Fixed Point Theory and Its Applications; Yokohama Publishers: Yokohama, Japan, 2000.

(C) 2019 by the authors. Licensee MDPI, Basel, Switzerland. This article is an open access article distributed under the terms and conditions of the Creative Commons Attribution (CC BY) license (http://creativecommons.org/licenses/by/4.0/). 